\title{
Artificial Neural Network based modelling of Earth Coupled Tube Heat Exchanger for Domestic Purposes
}

\author{
Hemant Parmar ${ }^{1}$, Pranesh Parmar $^{2}$ \\ ${ }^{l}$ Department of Mechanical Engineering, Ujjain Engineering College, Ujjain (M.P.)- India \\ ${ }^{2}$ B.Tech., Mechanical Engineering, Indian Institute of Technology, Mumbai (Maharastra)- India \\ ${ }^{1 *}$ Corresponding Author: e-mail: hemant_parmarl@ @rediffmail.com \\ 2 Author: e-mail: praneshparmar99@gmail.com \\ Tel.No.- +91 - 0734 - 2511912 Fax : +91 - $0734-2511912$
}

\begin{abstract}
Passive cooling techniques in buildings are the next alternative option against energy crises in the future. These techniques have energy saving opportunities as well as environment friendly for sustainable future. The water is the main component of day to day life in the domestic sector. In summer and winter season, a significant temperature difference obtained in domestic water with normal room temperature. This research work presented a system which is coupled with earth and benefitted by the heat transfer from the earth to system and vice-versa. The maximum reduction of outlet water temperature was obtained as $13{ }^{\circ} \mathrm{C}$ from the system. This system gives temperature difference of minimum $17 \%$ to a maximum of $34 \%$ of the inlet temperature. Experimental results are analyzed and on the basis of these results, an ANN based neural network was trained with three algorithms available in MATLAB i.e. trainlm, trainr and trainrp as the training function. A comparative analysis of performance of the system was conducted with these three algorithms. The mean square error (MSE) was selected as the performance index of training of network. The optimized MSE of the feed forward back propagation network was 2.14 for trainr training algorithm.
\end{abstract}

Index Terms- Earth tube heat exchanger, Passive cooling and heating techniques, Mathematical modelling, Artificial Neural Network, Training algorithm, Network Training.

\section{INTRODUCTION}

The Earth Coupled Water Tube Heat Exchanger (ECWTHE) is a device that maintains water at a comfortable condition by giving to or taking up heat from deeper layers of soil where temperature of earth is nearly constant. It uses the Earth's near constant subterranean temperature to warm or cool water or other fluids for residential, agriculture or industrial uses. It is known that temperature of soil strata between $2 \mathrm{~m}$ to $3 \mathrm{~m}$ depth has a stable temperature regime suitable for installation of ECWTHE. Temperature in this stratum displays no diurnal fluctuation. The system primarily uses the earth as a heat source (in the winter) or a heat sink (in the summer). Ground-coupled heat exchanger may also use air or antifreeze as a heat transfer fluid.

Many experiments were conducted on investigation of a coupled geothermal cooling system with earth tube and solar chimney by $\mathrm{Yu}$ Y. et al [1] with an existing test facility in summer to evaluate the performance of the system, in terms of passive cooling capability, active cooling capability, and soil thermal capability. The design and environmental evaluation of earth-toair heat exchangers (EAHE) analysed by Peretti C. et al [2].There is a rising interest in heating and cooling systems based on renewable energy sources. Air heating or cooling with earth-to-air heat exchangers (EAHE) is one approach for reducing ventilation heat losses and improving thermal comfort in buildings.

A new void fraction correlation inferred from artificial neural networks for modeling two-phase flows in geothermal wells studied by Castillo A.A.D. et al [3]
The target ANN output was defined by the optimized void fraction values ( $\alpha o p t$ ), which were calculated from the numerical modeling of two-phase flow using GEOWELLS (a wellbore simulator). The LevenbergMarquardt algorithm, the hyperbolic tangent sigmoid, and the linear activation functions were used for the development of the ANN model. The best ANN learning was achieved with an architecture of six neurons in the hidden layer, which made it possible to obtain a set of void fractions with a good accuracy $\left(R^{2}=0.9722\right)$.

Belatrache D. et al [4] presented the modeling and simulation of an earth air heat exchanger (EAHE), employed as an air-conditioning device for buildings in the climate conditions of the south of Algeria. The results of performance and overall energy savings are presented. The maximum daily cooling capacity of the EAHE studied was $1.755 \mathrm{kWh}$. Results showed that a simple EAHE system can provide $246.815 \mathrm{kWh}$ in a period of one year.

Ascione F. [5] analysed a case study concerning a multipurpose building located in Palermo (Southern Italy), and evaluates the benefits related to the use of an earth-to-air heat exchanger in a NZEB, in terms of energy saving and reduction of $\mathrm{CO}_{2 \text {-equivalent }}$ emissions, for a Mediterranean climate.

Shazib Uddin M. [6] investigated the thermal comfort performance of indoor air using the earth to air heat exchanger installation in developing country Bangladesh and life cycle energy and GHG emission analysis using cradle to grave life cycle assessment technique. The system is able to bring the air from two 


\section{Available online at www.ijrat.org}

extreme conditions; $11{ }^{\circ} \mathrm{C}, 91 \% \mathrm{RH}$ in winter and $34{ }^{\circ} \mathrm{C}, 77 \%$ RH in summer to human comfort condition and performed well in an office room.

The system may use metallic, PVC or concrete piping. With any of the above the system is quite economical. The system gives higher efficiency with metallic piping due to its high thermal conductivity and higher temperature gradient obtained. The presented Earth coupled water tube heat exchanger (ECWTHE) system consists of single pass metallic pipe whose one end is connected to the overhead tank that contains hot water. The pipe of sufficient length is buried under earth to a considerable depth and the section of the pipe which is open to atmosphere is insulated using glass wool. The buried section of the pipe acts as a heat exchanger rejects heat to the ground and brings it to a comfortable condition for various uses. The other end of the pipe is connected to point of application.

\subsection{Problem Identification}

Normally in summer season a problem is encountered that water in overhead tanks gets very hot, this water becomes unsuitable for use in domestic purposes. Similarly in cold countries the temperature of water during winters is quite low, which is again a problem.

The presented system helps to easily and economically solve the problem and brings the water temperature in a range that is comfortable for use.

\section{EARTH COUPLED WATER TUBE HEAT EXCHANGER (ECWTHE)}

Earth coupled water tube heat exchanger (ECWTHE) usually consists of loops of pipe buried in the ground horizontally or vertically. Vertical loops go deeper. Horizontal loops are usually buried at one to four meter depth. Temperature regime at this depth and beyond is stable, with no diurnal fluctuation and with only a small seasonal or annual variation. This stability is a result of natural physical phenomena. In the present work, an ECWHE was investigated the actual cooling performance of water. This ECWHE is made of $12 \mathrm{~m}$ long galvanized iron pipe of $12.7 \mathrm{~mm}$ nominal diameter. It is buried $0.60 \mathrm{~m}$ deep below the surface. Specific aim of this investigation is to determine the operating characteristics of ECWHE in heating mode.

Soil temperature, at depth of about 3-4 feet or more, says constant throughout the year, and is approximately equal to the average annual ambient water temperature. The ground can be used as a heat sink for cooling in the summer and as a heat source for heating in winter. A simple method of using this concept is to pass hot water through underground tunnel. The hot water cooled directly by heat transfer through conduction and convection in pipe and soil. This experimental work performed at Ujjain Engineering College, Ujjain (M.P.)-India.
In the summer season the water of overhead tank become so hot that it is not suitable to use for domestic purpose easily. So it is beneficial to setup a system which cools this hot water through efficient energy saving technique. A pipe was buried (through which water is flowing) at a depth of $0.6 \mathrm{~m}$ underground. Due to heat transfer of hot water heat in soil temperature of water get reduced up to comfortable level than it can be easily used for all purpose.

\section{OBJECTIVES OF RESEARCH WORK}

The objectives of the research work are -

1. To study and check feasibility of ECWTHE for variable conditions.

2. Artificial Neural Network (ANN) Based modelling of the system to predict expected output from the system within range of experimental observation. The trained Neural Network can be generalizing for obtaining expected output and can be used for design of the system at any location.

\section{METHODOLOGY ADOPTED}

An experimental work was performed on earth coupled water tube heat exchanger to achieve comfortable condition in the domestic sector. A water tube of mild steel was dug into the earth up to $0.60 \mathrm{~m}$ for achieving the benefits of earth soil which has the constant temperature and on the earth surface developed a garden. A constant temperature may be obtained below the earth surface. The gravity flow of water from the water tank was done to the utility point. For the experimental work, a $2 \mathrm{~kW}$ heater was used to increase the temperature of water and supply this water to the buried pipe inside the earth. The observations at the inlet and outlet were obtained with the help of thermocouples and measuring flask. On the basis of experimental performance, an Artificial Neural Network (ANN) based model was developed to predict the output temperature of the system. The training of neural network was completed with different training algorithms available in MATLAB. The training weights were assumed for training of the network and optimized for minimum performance index. These optimized weights were used for predicting the output from the system. In this modelling work, three training algorithms i.e. trainr, trainrp and trainlm were considered for training of the network. The performance of these training algorithms was compared on the basis of mean square error and suggested a suitable training algorithm for such type of data.

\section{EXPERIMENTAL SETUP AND OBSERVATIONS}

The complete details of experimental setup are shown in Figure 1. 


\section{Available online at www.ijrat.org}

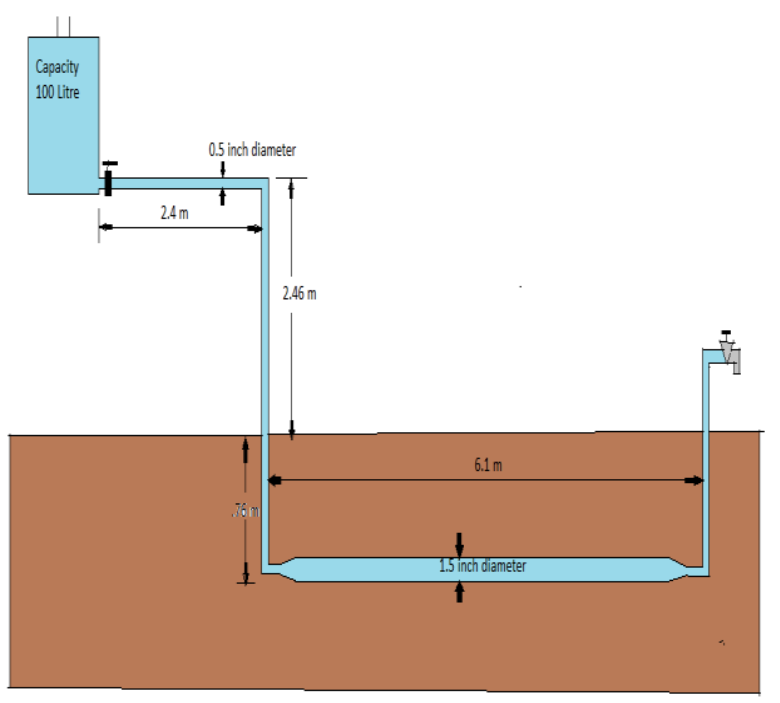

Fig.1 Block diagram of experimental setup.

It is an overhead water tank of capacity 100 litres. The water is used for the experiment is stored in this tank. It provides potential energy to the water for free flow through the tube. Water in the tank may be heated due to solar radiation or by artificial means.

In this heat exchanger the heat is exchanged between fluid in pipe and soil, with the help of conduction and free convection heat transfer. It is 6.1 meters in length and 1.5 inch in diameter.

Temperature of the fluid in the experiment is measured at two positions,

a. In the tank or at inlet to the heat exchanger.

b. At outlet to heat exchanger or at point of use.

The measurement of temperature will be done with the help of mercury thermometer.

To vary the flow according to our requirement we use the flow control valve. The valve is installed near the entry to the heat exchanger and also at outlet.

The experimental observations were recorded and shown in Table 1.

\begin{tabular}{|c|c|c|c|c|}
\hline $\begin{array}{r}\text { S. } \\
\text { No. }\end{array}$ & $\begin{array}{l}\text { Input } \\
\left({ }^{\circ} \mathrm{C}\right)\end{array}$ & temperatures & $\begin{array}{l}\text { Output } \\
\left({ }^{\circ} \mathrm{C}\right)\end{array}$ & temperatures \\
\hline 1. & & 34 & & 28 \\
\hline 2. & & 36 & & 30 \\
\hline 3. & & 37 & & 30 \\
\hline 4. & & 38 & 28 & \\
\hline 5. & & 39 & 27 & \\
\hline 6. & & 40 & 31 & \\
\hline 7. & & 42 & 34 & \\
\hline 8. & & 43 & 32 & \\
\hline 9. & & 44 & 31 & \\
\hline 10. & & 45 & 33 & \\
\hline 11. & & 47 & 27 & \\
\hline 12. & & 49 & 32 & \\
\hline 13. & & 50 & 34 & \\
\hline 14. & & 51 & 35 & \\
\hline 15. & & 52 & 35 & \\
\hline
\end{tabular}

Experimental performance of the system is shown in Fig. 2 with their mathematical modelling.

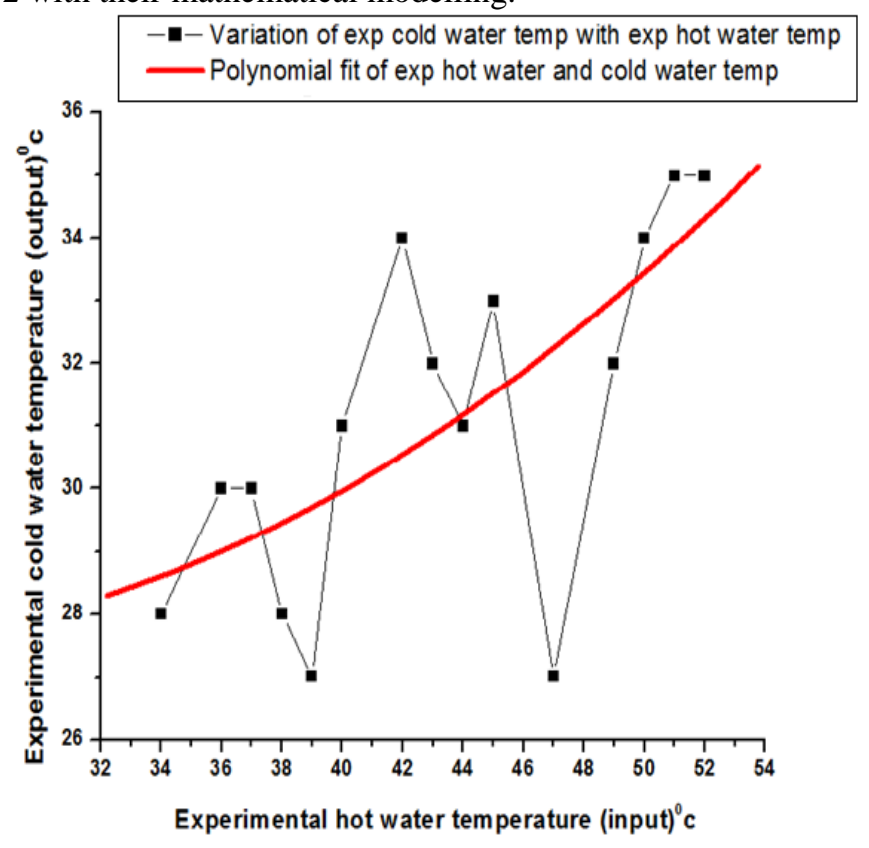

Fig 2: Variation between experimental input (hot) and output (cold) water temperature.

Experimental performance of the ECTWHE system can be shown by the mathematical equation (1).

$\mathrm{T}_{\text {cold }}=30.95521-0.32188 \mathrm{~T}_{\text {hot }}+0.00743 \mathrm{~T}_{\text {hot }}{ }^{2}$

The expected output temperature of the system can be calculated with the help of inlet hot water temperature.

\section{BASICS OF ARTIFICIAL NEURAL NETWORK (ANN)}

Artificial neural networks (ANN) are composed of simple elements operating in parallel. These elements are inspired by biological nervous systems. As in nature, the network function is determined largely by the connections between elements. A neural network can be trained to perform a particular function by adjusting the values of the connections (weights) between elements.

Commonly neural networks are adjusted, or trained, so that a particular input leads to a specific target output. The network is adjusted, based on a comparison of the output and the target, until the network output matches the target. Typically many such input/target pairs are used, in this supervised learning, to train a network [7]. The block diagram of neural network structure is shown in Fig. 3. 


\section{Available online at www.ijrat.org}

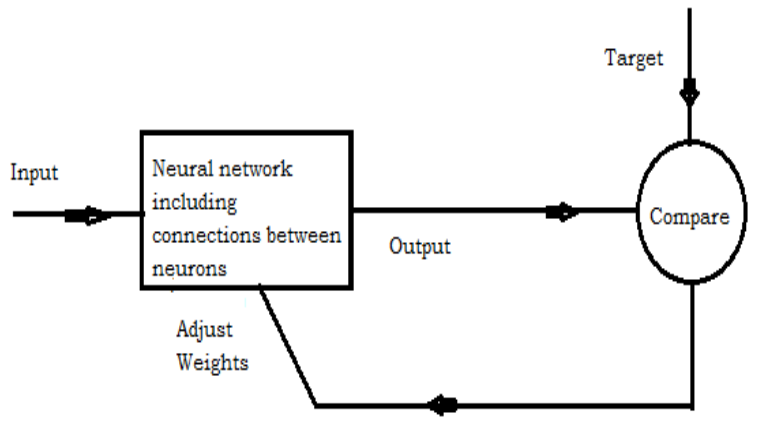

Fig.3 Block diagram of neural network.

Batch training of a network proceeds by making weight and bias changes based on an entire set (batch) of input vectors. Incremental training changes the weights and biases of a network as needed after presentation of each individual input vector. Incremental training is sometimes referred to as "on line" or "adaptive" training.

Neural networks have been trained to perform complex functions in various fields of application including pattern recognition, identification, classification, speech, vision and control systems. Today neural networks can be trained to solve problems that are difficult for conventional computers or human beings. Throughout the toolbox emphasis is placed on neural network paradigms that build up to or are themselves used in engineering, financial and other practical applications.

The utility of artificial neural network models lies in the fact that they can be used to infer a function from observations. This is particularly useful in applications where the complexity of the data or task makes the design of such a function by hand impractical.

Like other machine learning methods, neural networks have been used to solve a wide variety of tasks that are hard to solve using ordinary rule-based programming, including computer vision and speech recognition.

\section{NEURAL NETWORK TOOLBOX}

Neural Network Toolbox provides functions and apps for modeling complex nonlinear systems that are not easily modeled with a closed-form equation.

In Neural Network Tool box, an event driven method were used for obtaining the output from network. A GUI based data manager was used for setting the input data. A feed forward back propagation type of network was selected and trained with default weights. Neural Network Toolbox supports supervised learning with feed forward, radial basis, and dynamic networks. It also supports unsupervised learning with selforganizing maps and competitive layers. With the toolbox can design, train, visualize, and simulate neural networks.
Use Neural Network Toolbox for applications such as data fitting, pattern recognition, clustering, time-series prediction, and dynamic system modeling and control. To speed up training and handle large data sets, can be distribute computations and data across multicore process or Fitting a Function. Neural networks are good at fitting functions and recognizing patterns. In fact, there is proof that a fairly simple neural network can fit any practical function.

\section{RESULTS AND DISCUSSIONS}

Artificial Neural Network (ANN) Modelling has been used to calculate the network output and corresponding errors using three different training functions i.e. trainlm, trainrp, trainr.

Network output obtained by using Artificial Neural Network Modelling is compared with the Experimental output to obtain the network efficiency for different training functions.

The experimental observations, trained network output and the corresponding errors using trainlm as training functions are shown in Table 2.

Table2: Comparison between experimental and neural network outputs for trainlm.

\begin{tabular}{lll}
\hline $\begin{array}{l}\text { Output } \\
\text { tempera } \\
\begin{array}{l}\text { tures } \\
\left({ }^{\circ} \mathrm{C}\right)\end{array}\end{array}$ & $\begin{array}{l}\text { Network } \\
\text { output }\left({ }^{\circ} \mathrm{C}\right)\end{array}$ & Errors \\
\hline 28 & & \\
30 & 28.21535 & -0.21535 \\
30 & 28.85063 & 1.149368 \\
28 & 29.10464 & 0.895365 \\
27 & 29.29387 & -1.29387 \\
31 & 29.46778 & -2.46778 \\
34 & 29.66735 & 1.332652 \\
32 & 30.23586 & 3.764136 \\
31 & 30.57656 & 1.423441 \\
33 & 30.76978 & 0.230219 \\
27 & 30.49803 & 2.501966 \\
32 & 29.95033 & -2.95033 \\
34 & 32.14974 & -0.14974 \\
35 & 33.41648 & 0.583522 \\
35 & 34.23983 & 0.76017 \\
\hline & 34.65696 & 0.343038 \\
\hline
\end{tabular}

The comparisons between experimental and network output is shown in Fig.4. The Mean Square Error (MSE) was considered as the main performance index of the performance of the network. 


\section{E-ISSN: 2321-9637}

\section{Available online at www.ijrat.org}

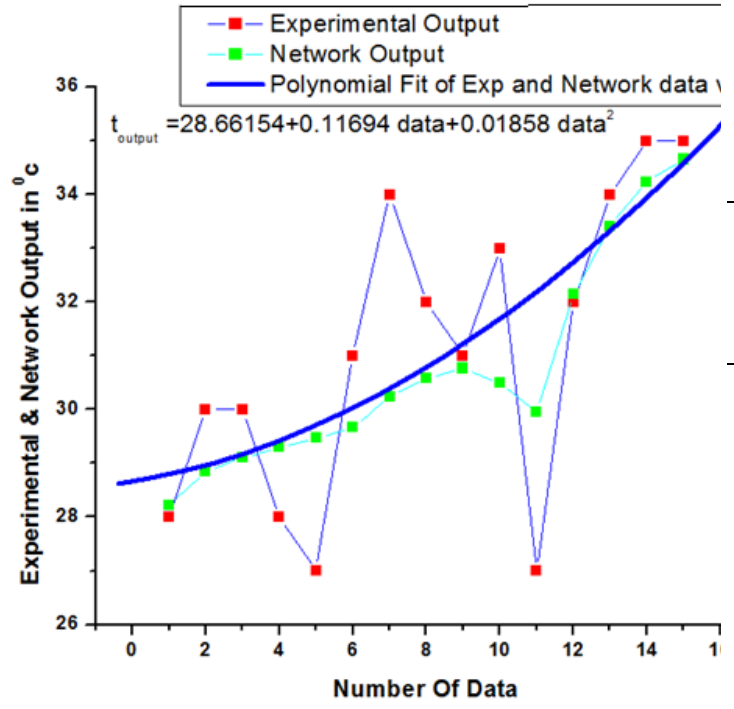

Fig.4 Variation of experiment and network output v/s no. of data for training function trainlm.

The output temperature of water may be written in terms of mathematical equation (2)-

$$
T_{\text {output }}=28.66154+0.11694 x+0.01858 x^{2}
$$

From the results, a very close agreement between the experimental and network output was found.

The variation of errors for each set of experimental and network output are shown in Fig.5.

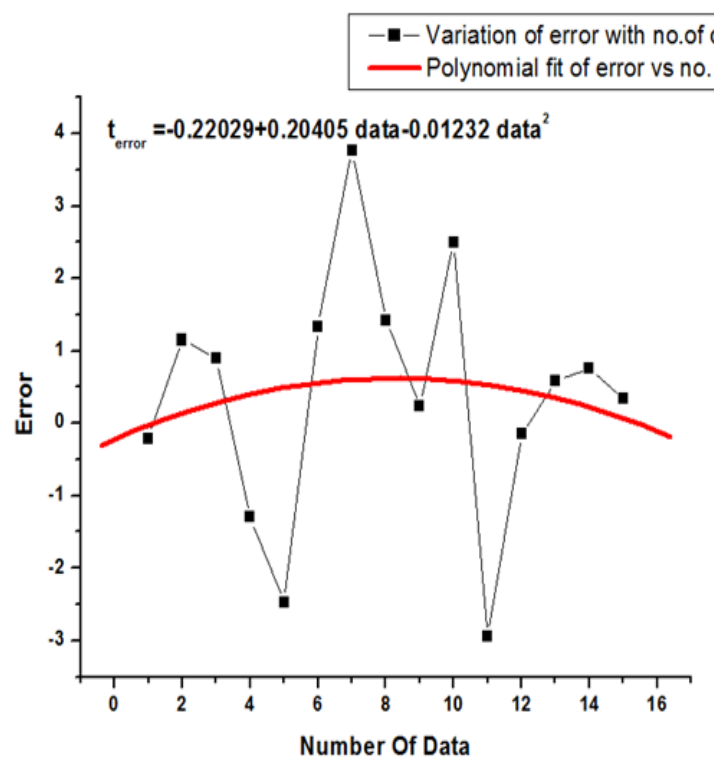

Fig. 5 Variation of error and no. of data for training function trainlm.

On the basis of the experimental data, a neural network was trained by using trainrp as training algorithm and obtained the network's output. The obtained data are shown in Table 3

Table 3: comparison between experimental and Neural network outputs for trainrp.

\begin{tabular}{lll}
\hline $\begin{array}{l}\text { Output } \\
\text { temper } \\
\text { atures } \\
\left({ }^{\circ} \mathrm{C}\right)\end{array}$ & $\begin{array}{l}\text { Network } \\
\text { output } \\
\left({ }^{\circ} \mathrm{C}\right)\end{array}$ & Errors \\
\hline 28 & 32.84253 & -4.84253 \\
30 & 30.304 & -0.304 \\
30 & 29.78001 & 0.219989 \\
28 & 29.5751 & -1.5751 \\
27 & 29.52933 & -2.52933 \\
31 & 29.60038 & 1.399619 \\
34 & 30.33678 & 3.66322 \\
32 & 31.11643 & 0.883568 \\
31 & 31.88728 & -0.88728 \\
33 & 32.37462 & 0.625379 \\
27 & 32.66597 & -5.66597 \\
32 & 32.41575 & -0.41575 \\
34 & 31.88985 & 2.110148 \\
35 & 30.77985 & 4.220148 \\
35 & 29.2505 & 5.749513 \\
\hline
\end{tabular}

A comparison of experimental and network output using trainrp as training function are shown in Fig.6.

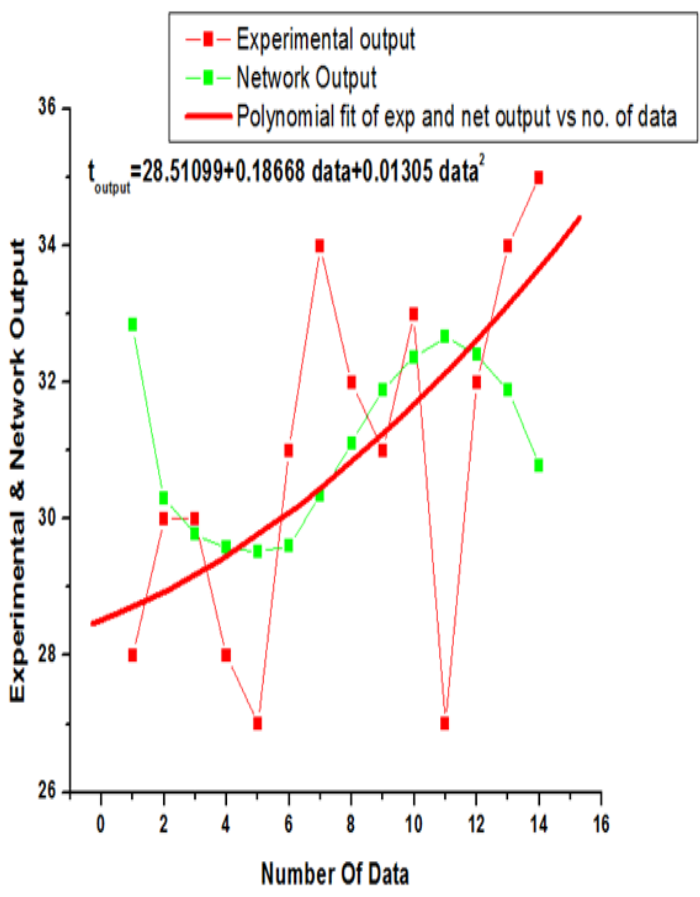

Fig. 6 Variation of experiment and network output v/s no. of data for training function trainrp.

A generalize equation for output temperature of water from the proposed system is shown in mathematical equation (3)-

$T_{\text {output }}=28.51099+0.18668 x+0.01305 x^{2}$ 


\section{Available online at www.ijrat.org}

From the Fig. 6 it was found that a close agreement was found between the experimental and network output.

The variation of errors for trainrp is shown in Fig. 7.

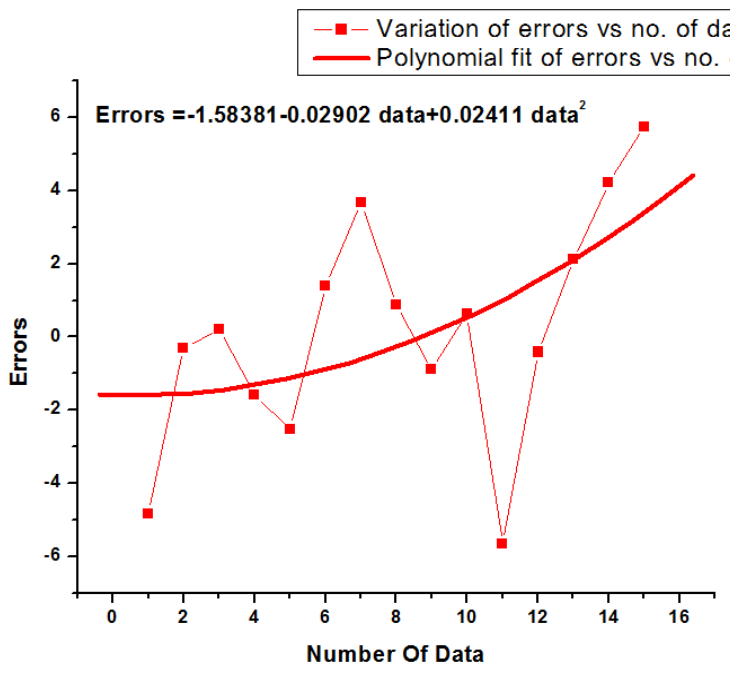

Fig.7 Variation of error and no. of data for training function trainrp.

Experimental data used for training of neural network and the output of the network are shown in Table 4 .

Table4: comparison between experimental and neural network outputs for trainr.

\begin{tabular}{clc}
\hline $\begin{array}{c}\text { Output } \\
\text { Temperatures } \\
\left({ }^{\circ} \mathrm{C}\right)\end{array}$ & $\begin{array}{l}\text { Network } \\
\text { output }\left({ }^{\circ} \mathrm{C}\right)\end{array}$ & Errors \\
\hline 28 & 29.14738 & -1.1473 \\
30 & 28.91324 & 1.08675 \\
30 & 28.65388 & 1.34612 \\
28 & 28.26508 & -0.2650 \\
27 & 27.83552 & -0.8355 \\
31 & 27.68117 & 3.31883 \\
34 & 33.2629 & 0.73709 \\
32 & 32.99631 & -0.9963 \\
31 & 31.1644 & -0.1644 \\
33 & 28.58251 & 3.41749 \\
27 & 28.59567 & -1.5956 \\
32 & 31.7221 & 0.27789 \\
34 & 34.53067 & -0.5306 \\
35 & 34.91549 & 0.08450 \\
35 & 34.95637 & 0.043635 \\
\hline
\end{tabular}

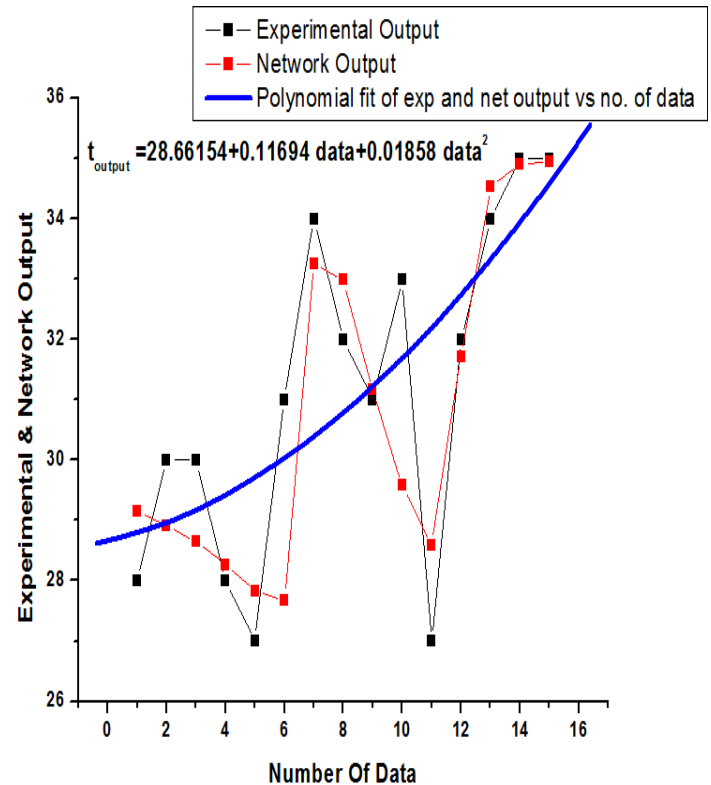

Fig. 8 Variation of experiment and network output v/s no. of data for training function trainr.

It was found that the experimental and network temperature of water are almost same and obtained minimum error.

The variation of errors using trainr as training function are shown in Fig.9.

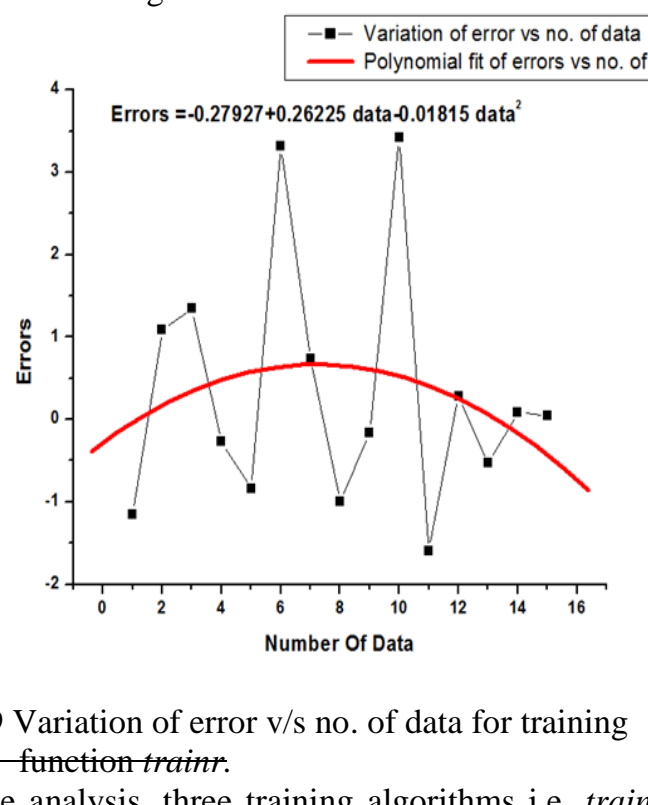

In the analysis, three training algorithms i.e. trainlm, trainrp and trainr were used for predict the output temperature of ECWTHE. The comparison of three different training algorithms are shown in Fig. 10.
The Fig. 8 shows the variation of experimenral and network output using tranr as training function. The output trmperature of water may be shown in equation (4)-

$$
T_{\text {output }}=28.66154+0.11694 x+0.01858 x^{2}
$$


Available online at www.ijrat.org

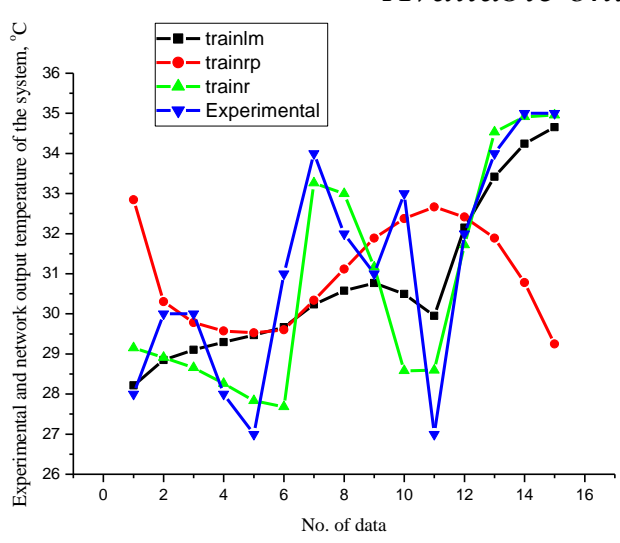

Fig. 10 Comparisons of different training algorithms with experimental data.

The minimum performance index (Mean square error) was obtained for trainr training algorithm i.e. 2.14. Random order incremental training with learning function (trainr) was suitable training algorithm for training of network for the data of earth coupled water tube heat exchanger for the range of experimental input/output.

\section{CONCLUSIONS}

ECWTHE was able to reduce the temperature of hot water of the overhead tank by as much as $13^{\circ} \mathrm{C}$ in summer. The basic soil temperature in April was $18^{\circ} \mathrm{C}$. The ECWTHE system is quite feasible and the cost calculated is also suitable for domestic installation. This system gives temperature difference of minimum $17 \%$ to a maximum of $34 \%$. The presented experimental model of ECWTHE is quite efficient for use as a summer water cooler and has very low losses.

The output from the experimental setup has been validated with artificial neural network model and it was found that the ANN based model shows the close agreement between experimental value and network value. The training of network with training function trainr was obtained minimum mean square error i.e. 2.14. The presented model can be used for any climatic conditions within range of experimental value. Since the flow of water in the system is due to gravity, the system does not involve energy consumption and is an eco-friendly system.

\section{REFERENCES}

[1] Yuebin Yu, Haorong Li, Fuxin Niu, Daihong Yu, 2014, "Investigation of a coupled geothermal cooling system with earth tube and solar chimney" Applied Energy, Volume 114, February 2014, Pages 209-217.

[2] Clara Peretti, Angelo Zarrella, Michele De Carli, Roberto Zecchin, 2013, "The design and environmental evaluation of earth-to-air heat exchangers (EAHE). A literature review", Renewable and Sustainable Energy
Reviews, Volume 28, December 2013, Pages 107 116.

[3] A. Álvarez del Castillo, E. Santoyo, O. GarcíaValladares, 2012, "A new void fraction correlation inferred from artificial neural networks for modeling two-phase flows in geothermal wells", Computers \& Geosciences, Volume 41, April 2012, Pages 25-39.

[4] Djamel Belatrache, Saïd Bentouba, Mahmoud Bourouis, 2017, "Numerical analysis of earth air heat exchanger at operating conditions in arid climates", International Journal of Hydrogen Energy, Volume 42, Issue 13,30 March 2017, Pages 8898-8904.

[5] Fabrizio Ascione, Diana D'Agostino, Concetta Marino, Francesco Minichiello, 2016, "Earth-toair heat exchanger for NZEB in Mediterranean climate", Renewable Energy, Volume 99, December 2016, Pages 553-563.

[6] Md. Shazib Uddin, Raju Ahmed, Masudur Rahman, 2016, "Performance evaluation and life cycle analysis of earth to air heat exchanger in a developing country", Energy and Buildings, Volume 128, 15 September 2016, Pages 254-261.

[7] Neural Network Toolbox by Howard Demuth, Mark Beale \& Martin Hagan. 